\title{
Quality Metrics in Agile Software Development Projects
}

\author{
Kristīne Kārkliņa ${ }^{1}$, Rūta Pirta ${ }^{2}$ \\ ${ }^{1,2}$ Riga Technical University, Riga, Latvia
}

\begin{abstract}
Nowadays, IT projects are becoming more complex and larger in scale. Stakeholders often experience difficulties assessing project quality attributes, such as progress, budget. Specifically adapted project metrics based on their descriptive features are beneficial tools for acquiring important information. The paper discusses metrics as an important project quality assessment method. It proposes using GQM method for selecting the most appropriate Agile project quality metrics. For metrics monitoring it explores popular cloud-based project management systems. An illustration of the approach is provided by two case studies with Agile projects in the public sector.
\end{abstract}

Keywords - Agile project management, project metrics, project management systems, public sector.

\section{INTRODUCTION}

Information technology (IT) has become a vital and integral part of every aspect of life, including the public sector. IT provides support for the day-to-day work of public administration, promotes information flow, accessibility, quality and ensures the reduction of administrative burden [1]. The development, operation support and improvement are carried out within IT projects in the public sector. Despite large investment in IT projects, a majority of them did not fit within scope, budget or schedule up to 2016. However, 2017 is the first year when the number of successfully managed projects has started to increase [2]. The main reasons are the improvement of technical and managerial knowledge, Agile project management methods and introduction of project management office (PMO) implementation in enterprises. PMO core tasks are resource, project plan, finance, communication and quality management, including project control using metrics. Although the Agile approach allows for a flexible approach to project planning and change management, reference points in the form of measurement metrics are needed to enable stakeholders to evaluate the project progress through various visual reports and charts.

Measurement methods allow evaluating actions undertaken and their results. However, it is difficult to identify the scope of project data and metrics needed to be calculated from these data to reach the desired goal. Collecting insufficient and excessive data can result in unnecessary costs. Therefore, for systematic metric selection GQM approach is used in the present paper.

Metrics can be derived, analyzed and presented using project management systems, which allow summarizing data, managing and supporting a wide range of project activities. In the present paper, nine systems are compared.
The aim of the paper is to propose an appropriate approach to metric identification and retrieval from project management systems in public sector projects.

The paper is organized in six sections. Section II covers theoretical basis of the case study, including Agile methodology, metrics, public sector characteristics. Section III considers related work to different measurement approaches. Section IV covers case study method description - metric definition using GQM method, metric measurement using project management systems, their features and comparison. The case study is described in Section V. Conclusions and recommendations on the assessment of quality and progress of the Agile projects in the public sector are drawn in Section VI.

\section{THEORETICAL BASIS}

\section{A. Agile Methodology}

Agile Alliance defines Agile as an ability to create and respond to change in order to succeed in an uncertain and turbulent environment [3]. Key concepts of Agile are daily meetings, work divided into functional increments called user stories, iterative and incremental development, close collaboration and milestone retrospective [3]. Some of Agile advantages are active stakeholder engagement, focus on people integration rather than processes and tools, adaption to changing circumstances and continuous attention to technical excellence [4], [5]. One of the most reported concerns is a lack of management control and predictability; therefore, effective communication between the team, its environment and costumer is crucial [6]. To counter any risks, it is necessary to implement a reporting mechanism to provide control over Agile development processes [6]. One of the project control methods is defining and measuring metrics.

\section{B. Metrics}

According to the IEEE standard [7], a software metric is a standard of measure of a degree to which a software system or process possesses some property. There is a wide range of metrics; therefore, it is advised to use a predefined approach to finding the right set of metrics [6]. Agile teams should design and use their own metrics in response to identified needs, rather than using pre-defined metrics [8]. A good metric should be easy measurable, tied to business goals; it should predict future business performance and be isolated from different factors [9]. One way to find the right metrics is to adopt GQM strategy that is further explained in Section IV.

Three most popular Agile metrics are velocity, sprint burndown chart and release burndown chart [10]. Velocity 
represents volume of work accomplished in a specified time; a sprint burndown chart shows progress of development during a sprint and a release burndown chart shows progress of development during the whole release [10].

Nowadays, most of project planning, task management, bug and error management, time tracking, information sharing and project control, including metric measurement, is done using project management systems.

\section{Project Management Systems}

PMI states that project management systems consist of tools and techniques used to gather, integrate and distribute the output of project management processes [11]. They support all aspects of the project from initiation to closing [11]. Organizations have various approaches and tools used for maintaining project information. These can be divided into two categories - 'undedicated tools' that are not originally designed for project management and 'dedicated tools' that are specifically designed for project management tasks [6].

Subsection A of Section IV covers comparison of dedicated tools based on their features.

\section{D.Public Sector}

Public organizations must be accessible and respond to the needs of the public [12]. Nowadays they experience a transition phase where tasks are changing and budget is shrinking; therefore, Agile approach is a solution to follow the latest developments and respond quickly [12].

When working with IT projects in the public sector, several factors should be considered that can significantly restrict and influence the project execution and management. Public sector institutions have a strong hierarchical organizational structure and role culture [1]. A project team needs to possess strong technological knowledge of multiple systems as integration between different department system needs to be made [1], [13]. Public sector software products have broad user base with different technical expertise and capability [13]. It is crucial to provide public sector products that are secure and can perform well during periods of high usage [13].

LaBrosse identifies a few challenges for making projects in the public sector Agile. Often projects have strict requirements, budget and scope that contradict with Agile philosophy that states "responding to change over following a plan" [14]. Bureaucratic and slow decision making in public sector organizations slows down the project execution making harder to keep up with a schedule [14]. The main focus of public sector IT area is to find a balance between reducing costs, realizing the desired social effects and improving product quality [12].

\section{RELATED WORK}

During time a number of frameworks, models and standards have been developed to support software projects in planning their measurement approach [15]. Most of the approaches tries to provide cost-effective measurement methods by collecting only useful data through metrics with a clear purpose. A large number of empirical studies have shown that goal-based measurement frameworks are effective and adaptable [15].
Some examples are Balanced Score Card (BSC), goal argument metric (GAM) and goal question metric (GQM) that will be later used in the case study. BSC is a framework that looks into several dimensions for describing, implementing, and managing a strategy at different levels of an organization by linking objectives, initiatives and measures [16]. GAM and GQM are similar because they are top down approaches that are interpreted from bottom up. In GAM, the goals and sub-goals are denoted as claims and then the analysis is focused on classifying which data and which properties of data (sub-goals) are needed to fulfill these claims [16]. GQM and GAM goals are referred to as a mission or project, while BSC goals are focused on a certain perspective in organizational hierarchy [16]. GQM is the most popular and widely used goal-based approach.

In the present paper, GQM is used because it derives clear quantitative results for later decision making and project management.

\section{PROPOSED APPROACH}

Usage of Agile metrics in the public sector is analyzed by considering two case studies. Suitability of project management systems for handling the agile metrics is investigated by analyzing typical reporting features. The selection of the metric is performed according to the goal question metric approach, which is described in Subsection A of Section IV. The metric selection process in relation to the project management system is described in Subsection C of Section IV.

\section{A. Metric Definition}

Goal question metric is based on an idea that first the desired goal is identified, then a set of questions that help determine how well the goal is achieved and finally the metrics that could help answer each question [17]. It is a top-down approach that consists of four phases, starting with 'planning' and 'definition' where metrics are defined based on the previously set goals and questions [6]. Two final stages are 'data collection' and 'interpretation' that include applying the metrics and comparing results with the defined GQM model in a bottom-up manner [6].

The technique can be applied to both traditional project management methods and Agile. However, Ambler identifies several things to keep GQM Agile [17]:

- automatically generated metrics are preferred over manually collected;

- as new information is gathered, goals and priorities should evolve;

- metrics should be available to a wide audience;

- metrics should be considered as an insight into project status that help while collaborating with the team.

In the case study represented in Section V, the main goals and questions are identified in consultation with stakeholders, but metrics have been selected based on previous studies, the experience of the authors and industry experts. 
TABLE I

COMPARISON OF Project MANAgEMENT SySTEM FEATURES

\begin{tabular}{|l|l|l|l|l|l|l|l|l|l|l|}
\hline No. & Feature & JIRA & Redmine & Axosoft & Assembla & Wrike & Asana & VersionOne & ActiveCollab & Taiga \\
\hline 1 & Collaboration tool & $\sqrt{ }$ & $\sqrt{ }$ & $\sqrt{ }$ & $\sqrt{ }$ & $\sqrt{ }$ & $\sqrt{ }$ & $\sqrt{ }$ & $\sqrt{ }$ \\
\hline 2 & Task management & $\sqrt{ }$ & $\sqrt{ }$ & $\sqrt{ }$ & $\sqrt{ }$ & $\sqrt{ }$ & $\sqrt{ }$ & $\sqrt{ }$ & $\sqrt{ }$ \\
\hline 3 & Time tracking & $\sqrt{ }$ & $\sqrt{ }$ & $\sqrt{ }$ & $\sqrt{ }$ & $\sqrt{ }$ & Plug-in & $\sqrt{ }$ & $\sqrt{ }$ \\
\hline 4 & Resource planning & $\begin{array}{l}\text { Plug- } \\
\text { in* }\end{array}$ & Plug-in & $\sqrt{ }$ & $\sqrt{ }$ & $\sqrt{ }$ & $\sqrt{ }$ & $\sqrt{ }$ & \\
\hline 5 & $\begin{array}{l}\text { Product backlog } \\
\text { management }\end{array}$ & $\sqrt{ }$ & Plug-in & $\sqrt{ }$ & $\sqrt{ }$ & $\sqrt{ }$ & $\sqrt{ }$ & $\sqrt{ }$ & \\
\hline 6 & Sprint management & $\sqrt{ }$ & Plug-in & $\sqrt{ }$ & $\sqrt{ }$ & $\sqrt{ }$ & $\sqrt{ }$ & $\sqrt{ }$ & $\sqrt{ }$ \\
\hline 7 & Bug/issue management & $\sqrt{ }$ & $\sqrt{ }$ & $\sqrt{ }$ & $\sqrt{ }$ & $\sqrt{ }$ & $\sqrt{ }$ & $\sqrt{ }$ & $\sqrt{ }$ \\
\hline 8 & Kanban board & $\sqrt{ }$ & Plug-in & $\sqrt{ }$ & $\sqrt{ }$ & $\sqrt{ }$ & $\sqrt{ }$ & $\sqrt{ }$ & $\sqrt{ }$ \\
\hline 9 & Gantt chart & $\begin{array}{l}\text { Plug- } \\
\text { in }\end{array}$ & $\sqrt{ }$ & $\sqrt{ }$ & Plug-in & $\sqrt{ }$ & $\sqrt{ }$ & $\sqrt{ }$ & Plug-in & $\sqrt{ }$ \\
\hline 10
\end{tabular}

* Plug-in is required to provide the feature.

\section{B. Comparison of Project Management Systems}

Due to a variety of project management systems, it is important to find the most appropriate one based on project specific needs and features.

Systems should be compared based on different factors features, cost, platform, performance, usability etc.; however, in this paper, for example, the nine most highly rated cloudbased project management systems are analyzed and compared based on ten features described below [18], [19], [20].

1. Collaboration tool. It supports teamwork, activities, communication to achieve a common goal through file sharing, messenger apps, team dashboards etc. Successful collaboration helps identify risks in timely manner, eliminates conflicts due to lack of communication and improves teamwork.

2. Task management. Function provides an ability to design, plan and manage project tasks, indicating their status, priority, time limit, person responsible, dependence on other tasks etc.

3. Time tracking. Function allows for time tracking, analysis and evaluation. Accurate time management can increase team productivity by simplifying bookkeeping tasks related to payroll calculations and billing.

4. Resource planning. Function endures the allocation of appropriate resources for activities and tasks to meet project requirements. These can be human resources, finances, production resources etc.
5. Product backlog management. Function provides product backlog management throughout the project.

6. Sprint management. It provides an ability to plan sprints, divide product backlog into smaller tasks and analyse performance during sprint.

7. Bug/Issue management. It is a process where information is obtained, bugs/issues are documented and managed that could occur in the developed product.

8. Kanban board. It provides optimization of the workflow using Kanban board visualization tool.

9. Gantt chart. The feature allows easily visualizing the project schedule in the form of a bar chart. It is considered a traditional project management methodology metric.

10. Reports. The function provides use of various reports implemented in the system, including the retrieval of metric data. Reports give information about project progress, quality and developers' work.

Project management systems are compared based on their features in Table I.

Then, the gathered data can be presented to stakeholders and the proper project management system can be chosen.

\section{Process Flow}

The provided approach can be represented as a process that is based on finding the proper project management tool by defining the necessary features and using GQM method for defining the right metrics for the proposed goals. 


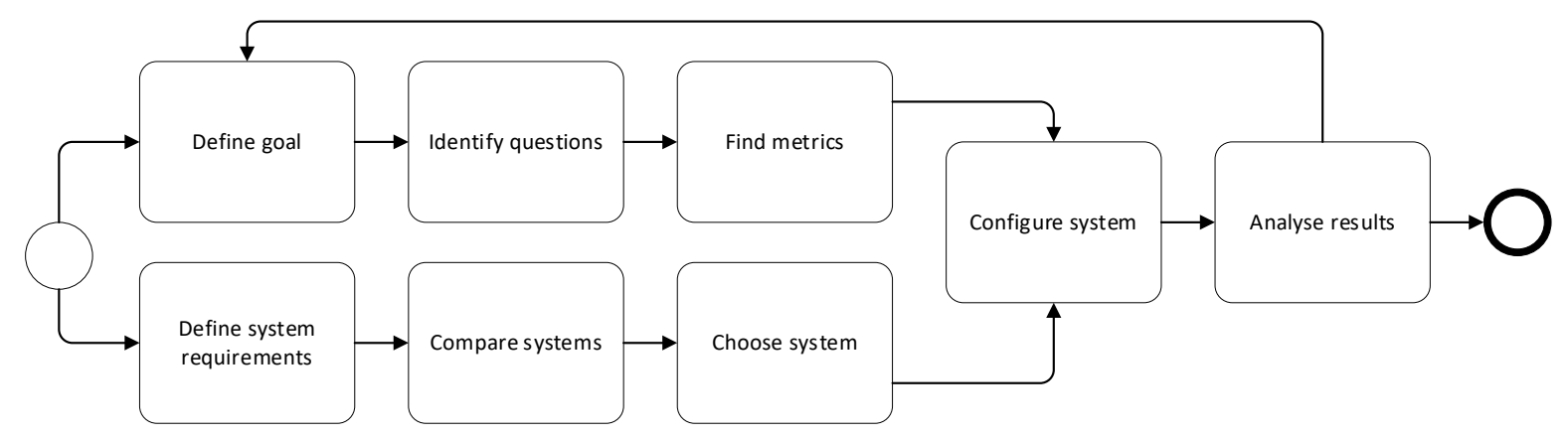

Fig. 1. Process workflow.

GQM as described in Subsection A consists of three stages goal definition, question identification and finding a metric. To measure metric effectively, a tool that allows for data retrieval and metric measurement is needed. The process of choosing a system can also be done in three stages - defining the necessary system requirements, comparing systems available on the market and choosing the system. Then, the chosen system can be configured to perform status reporting using defined metrics. It is necessary to analyze results, compare with the defined goal and change it when needed. The process is shown in Fig. 1. This approach is used in the case study in Section V.

\section{The CASE StUdy}

\section{A. Projects}

Within this case study, two public sector agile projects have been selected, both different by their size, goal, budget, team size and other parameters. Information about projects is summarized in Table II.

TABLE II

PROJECT CHARACTERISTICS

\begin{tabular}{|l|l|l|}
\hline Feature & Project A & Project B \\
\hline Goal & $\begin{array}{l}\text { Website for } \\
\text { cooperation between } \\
\text { users and public sector } \\
\text { institution }\end{array}$ & $\begin{array}{l}\text { System for securing a } \\
\text { transnational market }\end{array}$ \\
\hline Time (sprints) & 8 & 8 \\
\hline Budget (EUR) & 100000 & 500000 \\
\hline Team size & 5 & 14 \\
\hline
\end{tabular}

During this case study, the main research questions are as follows:

1. Can GQM approach be implemented in Agile software development projects in the public sector?

2. Are results accurate and can they be used for project management and decision making?

\section{B. GQM Process and Results}

The GQM method is used to identify metrics. It is described in detail in Section IV. Goals in both projects have been defined during unstructured interviews with public sector representatives. The questions and the most appropriate metrics that give answers to the questions raised are chosen by the authors according to the required results. Project A results are represented in Table III, while project B results - in Table IV.

As the authors have had different attributes to monitor and measure, the goals have been different in both projects. In project A, the authors' main focus has been testing support and quality control; however, in project B tasks have been broader and involved project progress, quality assessment, and developers' work assessment.

The number of metrics has been limited to maximum of five in each of the projects as a larger number can lead to problems with processing all the information. Metrics have been chosen or made based on the defined questions.

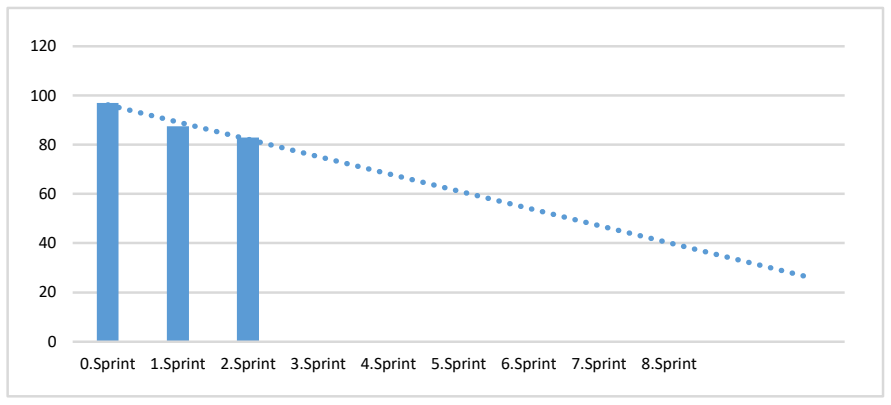

Fig. 2. Release burndown chart, project A.

In project $\mathrm{A}$, two main goals have been defined that cover testing and overall project plan execution control. As a result, four metrics have been developed, both traditional agile metrics such as a release burndown chart (Fig. 2) and project specific metrics such as passed/failed test cases (Fig. 3).

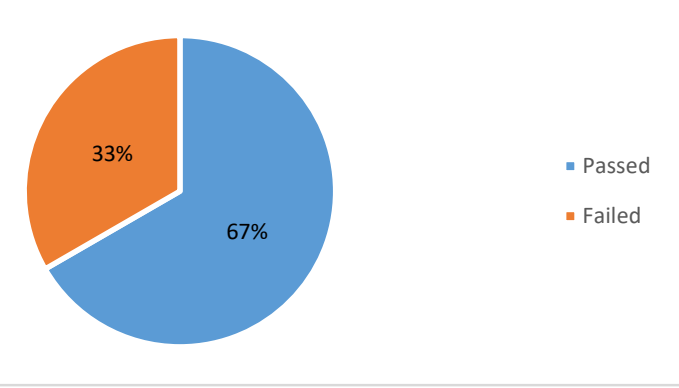

Fig. 3. Passed/failed test case metric, project A. 
The results obtained after two sprints in project A lead to several conclusions:

1. Requirements are not sufficiently elaborated and the project is behind the planned schedule;

2. Tasks are planned unevenly, leaving most of them scheduled for the last sprints.

All the conclusions present the risk of not developing the project successfully - meeting all defined requirements or deadline.

TABLE III

RESUlts of ProjeCt A

\begin{tabular}{|c|c|c|c|}
\hline Goal & Question & Metric & $\begin{array}{l}\text { Results (after } 2 \\
\text { sprints) }\end{array}$ \\
\hline \multirow[t]{2}{*}{$\begin{array}{l}\text { 1. To perform } \\
\text { testing of all } \\
\text { technical } \\
\text { requirements }\end{array}$} & $\begin{array}{l}\text { 1.a. How } \\
\text { productive is the } \\
\text { development of } \\
\text { requirements? }\end{array}$ & $\begin{array}{l}\text { Passed/failed } \\
\text { test cases }\end{array}$ & $\begin{array}{l}\text { High number of } \\
\text { failed tests }\end{array}$ \\
\hline & $\begin{array}{l}\text { 1.b. How critical } \\
\text { are the failed } \\
\text { tests? }\end{array}$ & $\begin{array}{l}\text { Failed test } \\
\text { case priorities }\end{array}$ & $\begin{array}{l}\text { High number of } \\
\text { high priority test } \\
\text { cases in the } 1^{\text {st }} \\
\text { sprint }(50 \%) \text {, in } \\
\text { the } 2^{\text {nd }} \text { sprint just } \\
\text { medium and low } \\
\text { priority test cases }\end{array}$ \\
\hline \multirow[t]{3}{*}{$\begin{array}{l}\text { 2. To perform } \\
\text { plan execution } \\
\text { control of } \\
\text { project } \\
\text { requirements }\end{array}$} & $\begin{array}{l}\text { 2.a. Are } \\
\text { requirements } \\
\text { scheduled for } \\
\text { development } \\
\text { according to the } \\
\text { plan? }\end{array}$ & \multirow[t]{2}{*}{$\begin{array}{l}\text { Task } \\
\text { breakdown } \\
\text { within sprints }\end{array}$} & $\begin{array}{l}\text { Tasks are not } \\
\text { planned evenly, } \\
\text { most is left for } \\
\text { last sprints }\end{array}$ \\
\hline & $\begin{array}{l}\text { 2.b. Are the } \\
\text { requirements } \\
\text { met according to } \\
\text { the plan? }\end{array}$ & & $\begin{array}{l}\text { The project is } \\
\text { behind the } \\
\text { scheduled } \\
\text { execution time }\end{array}$ \\
\hline & $\begin{array}{l}\text { 2.c. Will project } \\
\text { be finished in } \\
\text { time? }\end{array}$ & $\begin{array}{l}\text { Release } \\
\text { burndown } \\
\text { chart }\end{array}$ & $\begin{array}{l}\text { A risk that } \\
\text { project will not } \\
\text { be developed } \\
\text { according to the } \\
\text { deadline }\end{array}$ \\
\hline
\end{tabular}

For project $\mathrm{B}$, three goals have been defined that cover project plan control, system quality monitoring, and developers' work quality assessment. The results are gathered using four metrics such as created/ executed tasks (Fig. 4.), task status breakdown (Fig. 5.) etc.

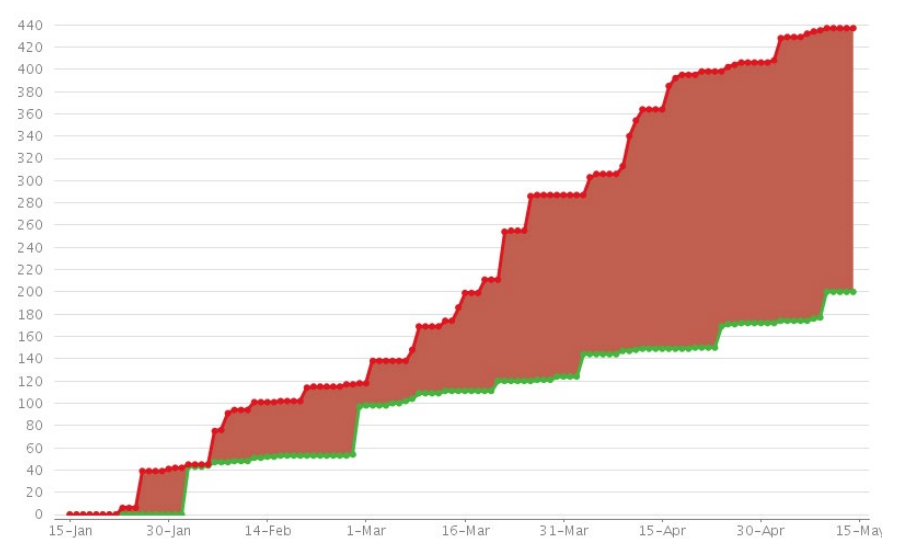

Fig. 4. Created/executed tasks metric, project B.

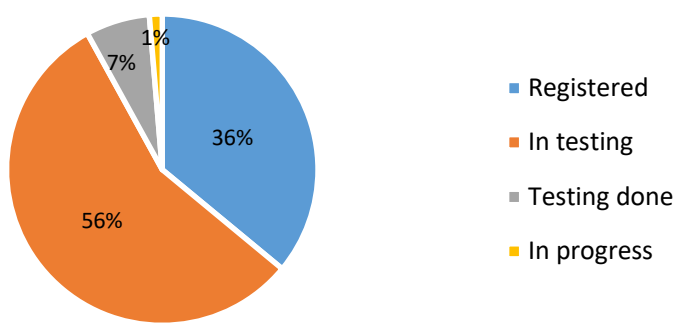

Fig. 5. Task status breakdown metric, project B.

In project $\mathrm{B}$, several conclusions can also be drawn based on metric results:

1. Project management system is not used according to Agile principles - backlog is not set at the beginning of the project, most of the tasks are added during sprints;

2. Project team regularly does not update task statuses;

3. Project execution is happening according to the plan. The first conclusion leads to the risk that the results do not show the actual situation in the project, therefore having a possibility of facing unpredictable problems.

\section{Project Management Systems}

In this case study, the results of the research described in Section III were presented to stakeholders.

In project $\mathrm{A}$, it was decided to use undedicated reporting tool- Excel for testing process control. Public sector representatives were reluctant to allocate project budget for additional project management tool.

In project $\mathrm{B}$, all interested parties agreed to use Jira project management system as they had previous experience with it.

TABLE IV

RESULTS OF PROJECT B

\begin{tabular}{|l|l|l|l|}
\hline Goal & Question & Metric & $\begin{array}{l}\text { Results (after the } 4^{\text {th }} \\
\text { sprint) }\end{array}$ \\
\hline $\begin{array}{l}\text { 1. To perform } \\
\text { project plan } \\
\text { execution } \\
\text { control }\end{array}$ & $\begin{array}{l}\text { 1.a. Does } \\
\text { the overall } \\
\text { product } \\
\text { backlog } \\
\text { decrease } \\
\text { over a } \\
\text { defined } \\
\text { time } \\
\text { frame? }\end{array}$ & $\begin{array}{l}\text { Created/executed } \\
\text { tasks }\end{array}$ & $\begin{array}{l}\text { Product backlog is } \\
\text { not created before } \\
\text { project start, the } \\
\text { system is not used } \\
\text { according to Agile } \\
\text { principles, team does } \\
\text { not update statuses } \\
\text { on a regular basis }\end{array}$ \\
\cline { 2 - 4 } & $\begin{array}{l}\text { 1.b. Does } \\
\text { the project } \\
\text { execution } \\
\text { happen } \\
\text { according } \\
\text { to the plan? }\end{array}$ & $\begin{array}{l}\text { Task status } \\
\text { breakdown }\end{array}$ & $\begin{array}{l}\text { Most of the tasks } \\
\text { solved (62\%) }\end{array}$ \\
\hline $\begin{array}{l}\text { 2. To perform } \\
\text { system quality } \\
\text { monitoring }\end{array}$ & $\begin{array}{l}\text { 2.a. How } \\
\text { many high } \\
\text { priority } \\
\text { tasks are in } \\
\text { the project? }\end{array}$ & $\begin{array}{l}\text { Task priority } \\
\text { breakdown }\end{array}$ & $\begin{array}{l}\text { 3.a. What } \\
\text { is the } \\
\text { average } \\
\text { execution } \\
\text { time for a } \\
\text { task? }\end{array}$ \\
$\begin{array}{l}\text { 3. To evaluate } \\
\text { effectiveness } \\
\text { of developers }\end{array}$ & $\begin{array}{l}\text { Average task life } \\
\text { span }\end{array}$ & $\begin{array}{l}\text { Inconsistent life } \\
\text { expectancy of tasks, } \\
\text { possibly rare status } \\
\text { renewal or } \\
\text { ineffective } \\
\text { development process }\end{array}$ \\
\hline
\end{tabular}




\section{RECOMMENDATIONS AND CONCLUSION}

The paper has presented the approach to metric identification using GQM method and data retrieval by means of project management systems. The case study has been conducted using two different public sector projects.

In the paper, two research questions have been defined whether GQM method can be implemented in Agile public sector projects and whether the results are accurate and can be used for decision making.

GQM method has successfully been implemented in both Agile sector projects; results have been retrieved and analyzed in the chosen project management systems and presented to stakeholders for further discussion. Therefore, it can be concluded that GQM approach proposed in the paper can be successfully used for quality control in Agile public sector projects.

Gathered results have been accurate and raised an awareness of stakeholders about situation in current sprint. However, results have been accurate for a given time frame and have not covered the whole project lifecycle. Results from metrics should be used in management and decision making; however, stakeholders should not completely rely on them. Therefore, the second research question can be answered partially as the research should be done during a longer time period.

Using GQM method in Agile projects helps understand and monitor the main objectives of the project, direct and monitor processes, achieve improvement goals, generate measures, which are useful for the defined goal attainment and easy manageable. However, there are also some GQM downsides. It becomes difficult to apply when stakeholders have no clear vision of the main goals of the project; selection of metrics is mostly subjective and can be argued on, as well as GQM lacks technological support.

The following recommendations are proposed:

- Stakeholders iteratively should review the defined goals.

- Metrics should evolve during the project when new information is gathered.

- Results must be seen as an informative insight into the project that can be used for later decision making.

The approach to metric identification and data gathering in Agile public sector software development projects can be improved by analyzing project results during a longer time frame and with more than one metric identification method that can be an objective of the further research.

\section{REFERENCES}

[1] O. Medvedska and S. Berzisa, "Selection of Software Development Project Lifecycle Model in Government Institution," Information Technology and Management Science, vol. 18, no. 1, pp. 5-11, 2015 https://doi.org/10.1515/itms-2015-0001

[2] Project Management Institute, "Success Rates Rise 2017 9th Global Project Management Survey," 2017.

[3] "What is Agile Software Development? | Agile Alliance." [Online]. Available:

[Accessed: 28-Aug-2018]
[4] S. Denning, "Why Agile Is Eating The World," Forbes, 2018. [Online]. Available: https://www.forbes.com/sites/stevedenning/2018/01/02/whyagile-is-eating-the-world/\#11994d9c4a5b. [Accessed: 28-Aug-2018].

[5] I. H. Sarker, F. Faruque, U. Hossen, and A. Rahman, "A survey of software development process models in software engineering," Int. J. Softw. Eng. its Appl., vol. 9, no. 11, pp. 55-70, 2015. https://doi.org/10.14257/ijseia.2015.9.11.05

[6] M. P. Boerman, Z. Lubsen, D. A. Tamburri, and J. Visser, "Measuring and Monitoring Agile Development Status," in 2015 IEEE/ACM 6th International Workshop on Emerging Trends in Software Metrics, 2015, pp. 54-62. https://doi.org/10.1109/wetsom.2015.15

[7] IEEE Standard for a Software Quality Metrics Methodology, IEEE standard 1061, 1992. https://doi.org/10.1109/IEEESTD.1993.115124

[8] P. Gregory, K. Taylor, H. Sharp, L. Barroca, and D. Salah, "From Performance to Value: Measuring in Agile," 2015.

[9] J. Trammell, "The 5 Characteristics of an Effective Business Metric," Inc., 2016. [Online]. Available: https://www.inc.com/joel-trammell/the-5characteristics-of-an-effective-business-metric.html [Accessed: 28-Aug-2018].

[10] W. Hayes, S. Miller, M. A. Lapham, E. Wrubel, and T. Chick, "Agile Metrics: Progress Monitoring of Agile Contractors," CMU/SEI-2013-TN029, Final rep., p. 58, January 2014. https://doi.org/10.21236/ADA609876

[11] A guide to the project management body of knowledge (PMBOK® guide), Project Management Institute Inc, 2000.

[12] R.-J. Poerstamper, "Agile society - Public sector - PwC," 2018. [Online]. Available: https://www.pwc.nl/en/industries/public-sector/themes/agilesociety.html. [Accessed: 29-Aug-2018].

[13] "4 Common Public Sector Software Challenges - iLAB," 2017. [Online]. Available: https://www.ilabquality.com/4-common-public-sectorsoftware-challenges/. [Accessed: 29-Aug-2018].

[14] M. LaBrosse and M. Alpine, "Can Government Projects Be 'Agile?," PMI Washington, DC, 2013. [Online]. Available: https://www.pmiwdc.org/article/michelle-labrosse-pmp-ceo-cheetahlearning-llc-pmi-rep ${ }^{\circledR}$-and-megan-alpine-ccpm-co-author/can-. [Accessed: 29-Aug-2018].

[15] C. Gencel, K. Petersen, A. Mughal, M. I. Iqbal, A. A. Mughal, and M. I. Iqbal, "A Decision Support Framework for Metric Selection in GoalBased Measurement Programs: GQM-DSFMS, " in Journal of Systems and Software, vol. 86, no. 12, pp. 3091-3108, 2013. https://doi.org/10.1016/i.jss.2013.07.022

[16] F. Yahya, R. J. Walters, and G. B. Wills, "Using Goal-Question-Metric (GQM) Approach to Assess Security in Cloud Storage," in V.Chang, M. Ramachandran, R. Walters, G. Wills (Eds), Enterprise Security, Lecture Notes in Computer Science, vol. 10131, Springer, Cham, 2017. https://doi.org/10.1007/978-3-319-54380-2_10

[17] S. Ambler, "Goal Question Metric ( GQM ) and Agile," 2016. [Online]. Available: http://www.disciplinedagiledelivery.com/agile-gqm/. [Accessed: 30-Aug-2018].

[18] S. Winstead, "13 Best Agile and Scrum Project Management Tools 2018 Update." [Online]. Available: https://myelearningworld.com/power-ofagile-project-management-in-e-learning-10-best-tools/. [Accessed: 29-Aug-2018].

[19] M. Shilova, "Project Management tools you should know in 2018 Apiumhub," 2017. [Online]. Available: https://apiumhub.com/tech-blogbarcelona/agile-project-management-tools/. [Accessed: 29-Aug-2018].

[20] E. O’Loughlin, "Web-Based Project Management Software SMB Report - 2016," 2016. [Online]. Available: https://www.softwareadvice.com/resources/web-project-managementsoftware-trends-2016/. [Accessed: 29-Aug-2018].

Kristīne Kārkliṇa obtained her BSc (2018) degree in Information Technology from Riga Technical University (Latvia). She works as an Assistant Project Manager at Emergn.

E-mail: kristine.karklina@emergn.com

Rūta Pirta is a Doctoral student at the study programme "Information Technology" of Riga Technical University. She obtained her MSc (2012) in Information Technology at Riga Technical University. She currently works as an IT Manager at audit and consulting firm PricewaterhouseCoopers.

E-mail: ruta.pirta@rtu.lv 